Open Access

\title{
The effect of trauma and patient related factors on radial head fractures and associated injuries in $\mathbf{4 4 0}$ patients
}

\author{
Izaäk F. Kodde ${ }^{1,2^{*}}$, Laurens Kaas ${ }^{3}$, Nick van Es ${ }^{2}$, Paul G.H. Mulder ${ }^{4}$, C. Niek van Dijk ${ }^{2}$ and Denise Eygendaal ${ }^{1}$
}

\begin{abstract}
Background: Radial head fractures are commonly interpreted as isolated injuries, and it is assumed that the energy transferred during trauma has its influence on the risk on associated ipsilateral upper limb injuries. However, relationships between Mason classification, mechanism of injury, and associated injuries have been reported only once before in a relatively small population. The purpose of this study was to define whether trauma mechanism and patient related factors are of influence on the type of radial head fracture and associated injuries to the ipsilateral upper limb in 440 patients.
\end{abstract}

Methods: The radiographs and medical records of 440 patients that presented with a fracture of the radial head were retrospectively analyzed. The medical records of all patients were searched for (1) the trauma mechanism and (2) associated injuries of the ipsilateral upper limb. The mechanism of injury was classified as being low-energy trauma (LET) or high-energy trauma (HET).

Results: Associated injuries to the ipsilateral upper limb were present in 46 patients (11\%). The mean age of patients with associated injuries (52 years) was significantly higher compared to patients without associated injuries (47 years) $(P=0.038)$, and female patients with a radial head fracture were older than males. Injury patterns were classified as LET in 266 patients (60 \%) and as HET in 174 patients. HETs were significantly more common in young men. Associated injuries were not significantly different distributed between HET versus LET $(P=0.82)$.

Conclusions: Injuries concomitant to radial head fractures were present in $11 \%$ of patients and the risk for these associated injuries increases with age. Trauma mechanism did not have a significant influence on the risk of associated injuries. Complex elbow trauma in patients with a radial head fracture seems therefore to be suspected based on patient characteristics, rather than mechanism of injury.

Keywords: Associated injury, Elbow, Mechanism of injury, Radial head fracture, Trauma

\section{Background}

Radial head fractures are common with an estimated incidence of 28-39 per 100.000 inhabitants per year [1, 2]. The trauma mechanism of radial head and neck fractures is by indirect impact along the radius, usually caused by a fall on the outstretched hand in pronation and elbow in slight flexion [3, 2]. Previous epidemiological studies by Duckworth et al. and Kaas et al.

\footnotetext{
* Correspondence: if.kodde@hotmail.com

'Department of Orthopedic Surgery, Upper Limb Unit, Amphia Hospital, Breda, The Netherlands

${ }^{2}$ Department of Orthopedic Surgery, Academic Medical Center, Post-box 226601100 DD Amsterdam, The Netherlands

Full list of author information is available at the end of the article
}

revealed a mean age of 43 - 48 years and a significantly higher age of female patients compared to males. Both authors questioned whether this phenomenon could be caused by osteoporosis $[2,1]$. In a subsequent case-control study including peripheral bone mineral density (BMD) measurements, radial head fractures in female patient above 50 years old were defined as potentially osteoporotic fractures [4].

Although radial head fractures are commonly seen as isolated injuries, associated injuries are reported in up to $92 \%$ of cases [5]. More complex injuries according to the Mason classification seem to be associated with other associated ipsilateral upper limb injuries [2]. Both the 
complexity of the fracture pattern as per the Mason classification and the risk of associated ipsilateral upper limb injuries are assumed to be related to the energy transferred during trauma. However, little is known about the effects of patient and trauma related factors on the complexity of the radial head fracture and associated injuries.

Since significant symptomatic associated injuries are present in only a minority of radial head fractures, it might be helpful for the clinician to increase the à priory suspicion for more complex elbow trauma based on patient and injury characteristics. The purpose of this study was therefore to define whether trauma mechanism and patient related factors are of influence on the type of radial head fracture and associated injuries to the ipsilateral upper limb. We hypothesized that associated injuries are more common in the elderly and patients that sustained a high-energy trauma. In order to answer these study questions, the current report describes the assessment and analysis of 440 patients with a fracture of the radial head.

\section{Methods}

Consecutive patients who presented with a fracture of the radial head at the emergency department (ED) of our hospital during a 4-year period were retrospectively identified. This level 2 trauma center provides a region of 400,000 inhabitants with acute medical care and is annually visited by approximately 44,000 patients. Trained residents in general and/or orthopedic surgery performed primary assessment and management of all patients at the ED. A trauma surgeon and an orthopedic surgeon reviewed the diagnosis and treatment. Inclusion criteria were radiographically confirmed acute fracture of the radial head and skeletal maturity. Patients with missing data about the mechanism of injury in their medical record or absence of initial radiographs were excluded. Approval for this study was waived by the ethics committee of the Amphia Hospital.

Radial head fractures on initial radiographs of the elbow obtained at the ED were classified according to the Mason classification [6]. The medical records (e.g. emergency notes) of all patients were searched for (1) the trauma mechanism and (2) diagnosis of associated injuries of the ipsilateral upper limb. Data extraction was performed by two of the authors. All radiographs of the ipsilateral upper limb and medical records were reviewed to identify possible associated injuries. Standardized radiographs with anteroposterior and lateral views were made in all patients. An additional radial head view was made in 120 patients and a CT-scan of the elbow in 30 patients. Additional imaging studies were not performed on a regular basis, but only if clinical assessment (e.g. physical examination) or primary radiographs indicated the probability of associated injuries. Retrospective assessment of radiographs was done by a senior orthopedic resident specially trained in radial head fractures. The mechanism of injury was noted as being low-energy trauma (LET) or high-energy trauma (HET), see Table 1 [2].

Statistical analysis (SPSS 20.0 IBM corporation, Armonk, NY, USA) was performed using the independent $T$-test and one-way ANOVA test to compare numerical data between groups of patients and the Fisher's exact test and Chi-squared test for categorical data. Odds ratios were obtained by logistic regression. In order to provide mutual independency between cases, only one of the cases with bilateral fractures was included in analyzes between groups. Results were considered statistically significant at $\mathrm{P}<0.05$.

\section{Results}

Over the selected period, the records of 450 patients that presented with a radial head fracture were reviewed. Ten patients were excluded since there was no information about the mechanism of injury reported. The mean and median age of the remaining 440 patients was 47 years (range 14-88, SD 16.5), and there were 278 (63\%) female patients. The mean age was 40 years for male patients, which was significant younger than the 52 years for female patients $(\mathrm{P}<0.001)$ (Fig. 1). Mason type-1 fractures were identified in 319 patients (73\%), type-2 fractures were seen in 84 patients (19 \%) and type-3 fractures in 37 patients $(8 \%)$. Associated injuries to the ipsilateral upper limb were present in 46 patients (11\%) and are summarized in Table 2 and an example of an associated injury (coronoid fracture) on radiographs in Fig. 2. Injury patterns were classified as LET in 266 patients $(60 \%)$ and as HET in 174 patients. Ten patients (2\%) had a radial head fracture following elbow dislocation. Thirteen patients $(3 \%)$ sustained two radial head fractures during the inclusion period. Since mutual independency between cases was required, only one fracture per patient was included in statistical analyzes between groups.

The mean age of patients with associated injuries (52 years) was significantly higher compared to patients without associated injuries (47 years) $(\mathrm{P}=0.038)$. The odds for an associated injury for each year increase in age in females was 1.031 (95\% CI: 1.006-1.057; P = 0.015) and in males 0.989 (95 \% CI: 0.950-1.029; $\mathrm{P}=0.59$ ). These odds ratios did not significantly differ between females and males $(\mathrm{P}=0.082)$. The age-adjusted odds ratio of females to males was 1.189 (95 \% CI: 0.532-2.660; $\mathrm{P}=0.67$ ).

Table 1 Classification of mechanism of injury

\begin{tabular}{ll}
\hline $\begin{array}{l}\text { Trauma } \\
\text { mechanism }\end{array}$ & Examples \\
\hline LET & $\begin{array}{l}\text { Fall from standing position, fall from chair, fall during } \\
\text { walking. }\end{array}$ \\
HET & $\begin{array}{l}\text { Fall from roof, motor vehicle accidents, fall from } \\
\text { bicycle or horse with speed, contact sports trauma. }\end{array}$ \\
\hline
\end{tabular}




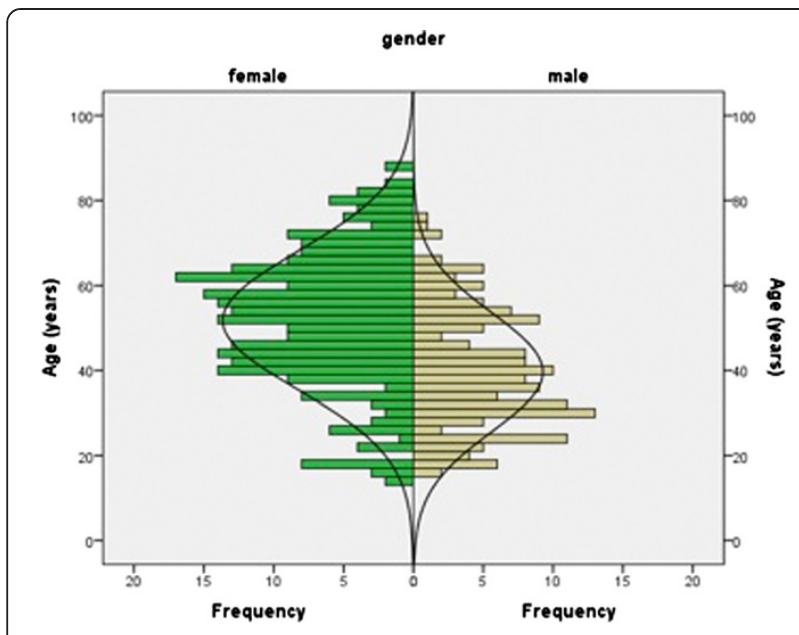

Fig. 1 Age distribution of patients with a radial head fracture

Table 3 illustrates the distribution of Mason fracture types for associated injuries. There was a significant difference in Mason fracture type comparing patients with and without associated injuries $(\mathrm{P}<0.001)$. Associated injuries were not significantly different distributed between HET versus LET $(\mathrm{P}=0.82)$ (Table 4).

Mean age of patients with a HET was 43 years compared to 51 years for LET $(\mathrm{P}<0.001)$. The distribution of HET versus LET was significantly different for males versus females, with more HET for male patients $(\mathrm{P}<0.001)$. There was no significant difference in Mason fracture type for HET versus LET. There were no age-specific differences for the type of Mason fracture $(\mathrm{P}=0.23)$.

\section{Discussion}

The radial head is an important secondary stabilizer of the elbow [7]. Especially in combination with deficiency of the collateral ligaments or coronoid fractures, elbow stability heavily relies on an intact radial head [8]. Accurate recognition and assessment of all associated injuries are necessary to initiate the correct treatment of the injury; early adequate management is mandatory to improve the clinical outcome $[8,9]$. The radial head fracture is, in general, believed to be an isolated, simple injury with a benign outcome. However, associated injuries with radial head fractures are increasingly recognized for their clinical significance [10-12]. The current study revealed an $11 \%$ risk of symptomatic associated injuries, which increases with age and Mason fracture type.

It is thought that the complexity of the injury is related to the amount of energy transferred during the trauma. However, in this study energy transfer during trauma was not related to associated injuries or Mason fracture type. Radial head fractures following HET occurred most frequently in young men. HET did not lead to more associated injuries or more complex radial head fractures than LET in the current study. The only predictors for more associated injuries were a higher Mason fracture type and a higher age. High-energy transfers through the elbow joint during trauma did not result in more concomitant injuries in young patients, in contrast to older patients that sustain LET more commonly. Based on these observations, we assume that additional injuries, next to radial head fractures, were also dependent on the intrinsic quality of bone and soft tissues and a frailty phenotype of the elderly patient. Therefore, complex elbow trauma in patients with a radial head fracture should be suspected based on patient characteristics rather than the mechanism of injury.

Mechanism of injury of radial head and neck fractures have been categorized by Duckworth et al. in low-energy (i.e. fall from standing height) and high-energy (e.g.

Table 2 Types and frequencies of associated injuries

\begin{tabular}{|c|c|c|c|c|}
\hline \multirow[t]{2}{*}{ Types of associated injuries. } & \multicolumn{2}{|c|}{ Mechanism of injury } & \multirow[t]{2}{*}{ Total (\%) } & \multirow{2}{*}{$\begin{array}{l}\text { Cumulative } \\
\text { percent }\end{array}$} \\
\hline & LET & HET & & \\
\hline Distal radius fracture & 4 & 0 & $4(8.7)$ & 8,7 \\
\hline Carpal fracture & 9 & 3 & $12(26.1)$ & 34,8 \\
\hline SL dissociation & 1 & 1 & $2(4.3)$ & 39,1 \\
\hline Proximal ulna fracture & 3 & 1 & $4(8.7)$ & 47,8 \\
\hline Coronoid fracture & 7 & 7 & $14(30.4)$ & 78,3 \\
\hline UCL injury & 0 & 1 & $1(2.2)$ & 80,4 \\
\hline LCL injury & 1 & 1 & $2(4.3)$ & 84,8 \\
\hline Coronoid + LCL injury (dislocation) & 0 & 3 & $3(6.5)$ & 91,3 \\
\hline Capitellum injury & 1 & 1 & $2(4.3)$ & 95,7 \\
\hline DRUJ dislocation (Essex Lopresti injury) & 1 & 0 & $1(2.2)$ & 97,8 \\
\hline Humeral fracture & 0 & 1 & $1(2.2)$ & 100,0 \\
\hline Total & 27 & 19 & 46 & \\
\hline
\end{tabular}




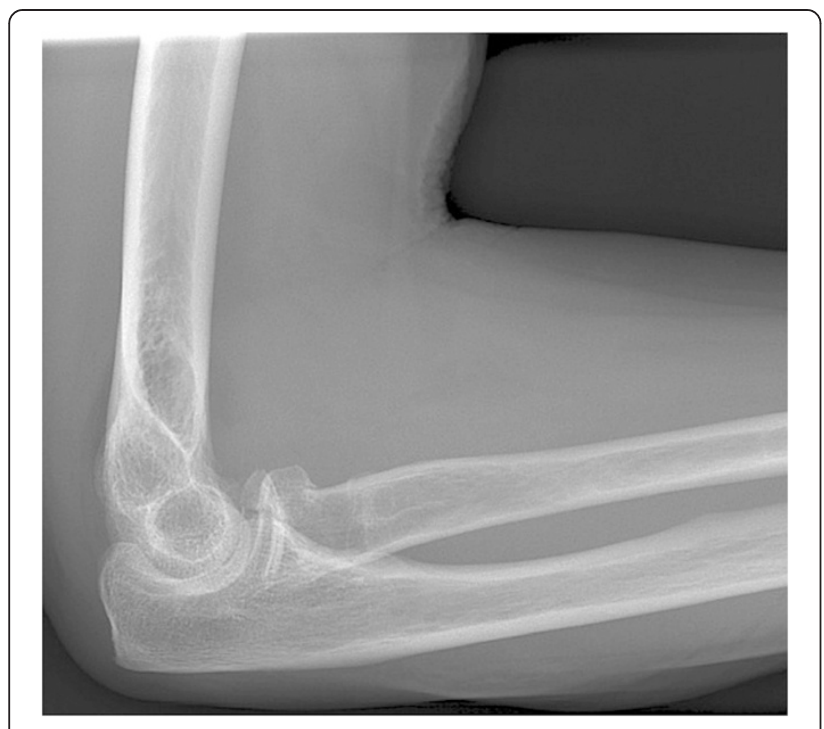

Fig. 2 associated injury (coronoid fracture) on radiograph

sports trauma or fall from height), as is done in the current study [2]. They observed significant more HETs in males, and HET was defined as a significant risk factor for associated injuries. HETs occurred in $43 \%$ of the 285 patients in their series and associated injuries were present in $7 \%$ of patients. The current study identified $40 \%$ of injuries as HET, and $11 \%$ of patients had associated injuries. However, HETs were no significant risk factors for additional injuries in this series. One explanation for this difference might be that Duckworth analyzed both radial head and neck fractures, whereas we included only radial head fractures. They suggested that radial neck fractures were - more than radial head fractures - low-energy fragility fractures. Another explanation might be that associated injuries occur by the direction of impact during trauma rather than by the amount of energy transferred during trauma. McGinley et al. found that axial impact in neutral position of the forearm resulted in isolated radial head fractures, whereas loading in pronation resulted in more comminuted fractures with associated lesions of the interosseous membrane [13]. Thus, how the energy is transferred may be more important than how much energy is transferred during trauma.

Table 3 Distribution of Mason fracture types for associated fractures

\begin{tabular}{lllll}
\hline & & \multicolumn{2}{l}{ Associated injury } & Total \\
& & - & + & \\
\hline Mason type & 1 & 289 & 19 & 308 \\
& 2 & 72 & 10 & 82 \\
& 3 & 20 & 17 & 37 \\
Total & & 381 & 46 & 427 \\
\hline
\end{tabular}

Table 4 Distribution of HET versus LET for associated injuries

\begin{tabular}{lllll}
\hline & & \multicolumn{2}{c}{ Associated injury } & Total \\
& & - & + & \\
\hline Mechanism of injury & LET & 230 & 27 & 257 \\
& HET & 151 & 19 & 170 \\
Total & & 381 & 46 & 427 \\
\hline
\end{tabular}

In this study, associated injuries were more frequently observed in the elderly, and female patients with a radial head fracture were older than males. These findings are in agreement with suggestions that radial head fractures are potentially osteoporotic fractures [4]. Gebauer et al. recently performed cadaveric studies on the microarchitecture of the radial head. BMD and histomorphometric analysis were performed on radial heads of three different groups of cadavers; aged 20-40 years, $41-60$ years, and 61-80 years. They showed a significant decrease in BMD with increasing age for men and women. Trabecular thickness significantly decreased with age, whereas trabecular separation significantly increased with age, leading to more radiolucency of the radial head on radiographs with aging. These age-related changes in microarchitecture of the radial head were suggested to reduce the biomechanical stability of the bone [14]. Since associated injuries were more commonly observed in older patients in the current study, we assume that older female patients with a radial head fracture overall have a diminished bone quality. As the extent of the injury varies with the position of the forearm during a fall, the way elderly fell may also account for the higher amount of associated injuries. Overall, a frailty phenotype is associated with a greater risk of fracture, disability and falls in elderly women [15]. It seems therefore critical to maintain optimal bone and soft tissues qualities, as well as overall physical condition, in the aging population in order to prevent more complex elbow injuries.

The more complex the radial head fracture is according to the Mason classification, the higher the frequency of associated injuries in the current study. Associated injuries were identified in almost half of the patients with a Mason type-3 fracture of the radial head. Kaas et al. noticed associated injuries on MRI in even $100 \%$ of patients with a Mason type-3 fracture [16]. Therefore, thorough evaluation of the elbow by a preoperative CT- or MRI-scan and/or intraoperative stability testing using fluoroscopy might be preferable to adequately deal with possible associated injuries in all Mason type-3 fractures. With regard to Mason type-2 fractures, Rineer et al. identified concomitant injuries in $77 \%$ of patients [17]. They divided Mason type-2 fractures in two groups based on the existence of cortical contact between the fracture fragment and the radial head. Fracture fragments without cortical contact led to a 21-times greater risk for associated 
injuries. Loss of cortical contact was in the current study seen in $37 \%(17 / 46)$ of patients with associated injuries, versus $6 \%(24 / 381)$ of patients without associated injuries. However, the distribution of radial head fractures among the Mason fracture types in the study from Rineer [17] is variant to those of Kaas [1], Duckworth [2], and the current study, as is the amount of associated injuries for Mason type-2 fractures. Nevertheless, as Rineer et al. concluded: 'if imaging studies fail to demonstrate the presence of a complex elbow injury pattern, the surgeon should still have a high suspicion that some degree of occult instability may be present' in Mason type-3 fractures and Mason type-2 without cortical contact [17].

The current study was with 440 included patients one of the largest studies on the epidemiology of radial head fractures $[2,1,18,19]$. The influences of mechanism of injury on radial head and neck fractures and associated injuries have only been once reported before [2]. The current study focused both on modes of injury and patient related factors on associated injuries for radial head fractures, leading to other findings. This study had several limitations in addition to its retrospective nature. First, associated injuries were documented based on available imaging studies instead of standardized radiographic studies for all patients. For instance, a standard MRI was not performed, and the LCL lesions in this study were identified as avulsion fractures from the epicondyle or during surgical reconstruction of Mason type 3 fractures. However, since most associated injuries are not clinically relevant, it is not advised to perform MRI scans on a regular basis for radial head fractures [10]. Second, the interobserver reliability of the Mason classification is known to be only moderate [20]. In addition, it might be difficult to take standardized radiographs of the elbow in the acute setting because of pain. Third, there is no clear definition of amounts of energy that are transferred during different mechanisms of injury. Moreover, the direction of impact (axial, direct, rotation of forearm, etc.) during trauma, may be more important to sustain associated injuries than the kind of trauma [21].

Future research should concentrate on Mason type-2 and type- 3 fractures and the association with clinically and therapeutically relevant associated injuries. The impact of energy transfer during trauma and its consequences on associated injuries should be established. The indications for additional imaging studies for these fractures need to be explored.

\section{Conclusions}

Injuries concomitant to radial head fractures were present in $11 \%$ of patients and the risk for these associated injuries increases with age. Furthermore, the risk for associated injuries increases with complexity of the radial head fracture according to the Mason classification. Trauma mechanism did not have a significant influence on the risk of associated injuries. Complex elbow trauma in patients with a radial head fracture seems therefore to be suspected based on patient characteristics, rather than mechanism of injury. Associated injuries should be actively be explored in older patients with Mason type- 2 or type- 3 fractures by means of physical examination of the whole ipsilateral arm and potential additional radiographic studies.

\section{Abbreviations}

(BMD): Bone Mineral Density; (Cl): Confidence Interval; (ED): Emergency Department; (HET): High-Energy Trauma; (LET): Low-Energy Trauma; (MRI): Magnetic Resonance Imaging; (SD): Standard Deviation.

\section{Competing interests}

The authors declare that they have no competing interests.

\section{Authors' contributions}

IFK: data analysis and preparation of manuscript. LK: study design and data collection. NVE: data collection and preparation of manuscript. PM: statistical analysis and revision of manuscript. CNVD: study design and revision of manuscript. DE: study design and revision of manuscript.

\section{Author details}

${ }^{1}$ Department of Orthopedic Surgery, Upper Limb Unit, Amphia Hospital, Breda, The Netherlands. ${ }^{2}$ Department of Orthopedic Surgery, Academic Medical Center, Post-box 226601100 DD Amsterdam, The Netherlands. ${ }^{3}$ Department of Orthopedic Surgery, University Medical Center Utrecht, Utrecht, The Netherlands. ${ }^{4}$ Consulting Biostatistician, Amphia Academy, Amphia Hospital, Breda, The Netherlands.

Received: 28 January 2015 Accepted: 28 May 2015

Published online: 05 June 2015

\section{References}

1. Kaas $L$, van Riet RP, Vroemen JP, Eygendaal D. The epidemiology of radial head fractures. J Shoulder Elbow Surg. 2010;19(4):520-3. doi:10.1016/j.jse.2009.10.015.

2. Duckworth AD, Clement ND, Jenkins PJ, Aitken SA, Court-Brown CM, McQueen MM. The epidemiology of radial head and neck fractures. J Hand Surg [Am]. 2012;37(1):112-9. doi:10.1016/j.jhsa.2011.09.034.

3. Amis AA, Miller JH. The mechanisms of elbow fractures: an investigation using impact tests in vitro. Injury. 1995;26(3)):163-8. doi:10.1016/0020-1383(95)93494-3.

4. Kaas L, Sierevelt IN, Vroemen JP, van Dijk CN, Eygendaal D. Osteoporosis and radial head fractures in female patients: a case-control study. J Shoulder Elbow Surg. 2012;21(11):1555-8. doi:10.1016/j.jse.2012.03.007.

5. Itamura J, Roidis N, Mirzayan R, Vaishnav S, Learch T, Shean C. Radial head fractures: MRI evaluation of associated injuries. J Shoulder Elbow Surg. 2005;14(4):421-4. doi:10.1016/j.jse.2004.11.003.

6. Mason ML. Some observations on fractures of the head of the radius with a review of one hundred cases. Br J Surg. 1954;42(172):123-32. doi:doi.

7. Morrey BF, An KN. Stability of the elbow: osseous constraints. J Shoulder Elbow Surg. 2005;14(1 Suppl S):174S-8S. doi:10.1016/j.jse.2004.09.031.

8. Morrey BF. Current concepts in the management of complex elbow trauma. Surgeon. 2009;7(3):151-61. doi:10.1016/S1479-666X(09)80039-5.

9. Kalicke T, Muhr G, Frangen TM. Dislocation of the elbow with fractures of the coronoid process and radial head. Arch Orthop Trauma Surg. 2007;127(10):925-31. doi:10.1007/s00402-007-0424-6.

10. Kaas $L$, van Riet RP, Turkenburg JL, Vroemen JP, van Dijk CN, Eygendaal D. Magnetic resonance imaging in radial head fractures: most associated injuries are not clinically relevant. J Shoulder Elbow Surg. 2011;20(8):1282-8. doi:10.1016/j.jse.2011.06.011.

11. Kaas $L$, van Riet RP, Vroemen JP, Eygendaal D. The incidence of associated fractures of the upper limb in fractures of the radial head. Strategies Trauma Limb Reconstr. 2008;3(2):71-4. doi:10.1007/s11751-008-0038-8.

12. van Riet RP, Morrey BF. Documentation of associated injuries occurring with radial head fracture. Clin Orthop Relat Res. 2008;466(1):130-4. doi:10.1007/s11999-007-0064-8. 
13. McGinley JC, Hopgood BC, Gaughan JP, Sadeghipour K, Kozin SH. Forearm and elbow injury: the influence of rotational position. J Bone Joint Surg Am. 2003;85-A(12):2403-9.

14. Gebauer M, Barvencik F, Mumme M, Beil FT, Vettorazzi E, Rueger JM, et al. Microarchitecture of the radial head and its changes in aging. Calcif Tissue Int. 2010:86(1):14-22. doi:10.1007/s00223-009-9304-0.

15. Tom SE, Adachi JD, Anderson Jr FA, Boonen S, Chapurlat RD, Compston JE, et al. Frailty and fracture, disability, and falls: a multiple country study from the global longitudinal study of osteoporosis in women. J Am Geriatr Soc. 2013;61(3):327-34. doi:10.1111/jgs.12146.

16. Kaas L, Turkenburg JL, van Riet RP, Vroemen JP, Eygendaal D. Magnetic resonance imaging findings in 46 elbows with a radial head fracture. Acta Orthop. 2010;81(3):373-6. doi:10.3109/17453674.2010.483988.

17. Rineer CA, Guitton TG, Ring D. Radial head fractures: loss of cortical contact is associated with concomitant fracture or dislocation. J Shoulder Elbow Surg. 2010;19(1):21-5. doi:10.1016/j.jse.2009.05.015.

18. Kovar FM, Jaindl M, Thalhammer G, Rupert S, Platzer P, Endler G, et al. Incidence and analysis of radial head and neck fractures. World J Orthop. 2013;4(2):80-4. doi:10.5312/wjo.v4.i2.80.

19. Duckworth AD, Watson BS, Will EM, Petrisor BA, Walmsley PJ, Court-Brown $C M$, et al. Radial head and neck fractures: functional results and predictors of outcome. J Trauma. 2011;71(3):643-8. doi:10.1097/TA.0b013e3181f8fa5f.

20. Doornberg J, Elsner A, Kloen P, Marti RK, van Dijk CN, Ring D. Apparently isolated partial articular fractures of the radial head: prevalence and reliability of radiographically diagnosed displacement. J Shoulder Elbow Surg. 2007;16(5):603-8. doi:10.1016/j.jse.2006.10.015.

21. Hausmann JT, Vekszler G, Breitenseher M, Braunsteiner T, Vecsei V, Gabler C. Mason type-I radial head fractures and interosseous membrane lesions-a prospective study. J Trauma. 2009;66(2):457-61. doi:10.1097/ TA.0b013e31817fdedd.

\section{Submit your next manuscript to BioMed Central and take full advantage of:}

- Convenient online submission

- Thorough peer review

- No space constraints or color figure charges

- Immediate publication on acceptance

- Inclusion in PubMed, CAS, Scopus and Google Scholar

- Research which is freely available for redistribution 